\title{
Considering Gender-Biased Assumptions in Evolutionary Biology
}

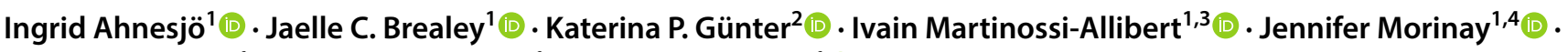 \\ Mattias Siljestam ${ }^{1} \cdot$ Josefine Stångberg $^{1} \cdot$ Paula Vasconcelos $^{1} \mathbb{D}$
}

Received: 6 November 2019 / Accepted: 22 January 2020 / Published online: 1 February 2020

(c) The Author(s) 2020

\begin{abstract}
Many organisms studied by evolutionary biologists have different sexes, and the evolution of separate sexes and sexual dimorphisms in morphology and behaviour are central questions in evolutionary biology. Considering scientists to be embedded in a social and cultural context, we are also subjected to the risk of gender-biased assumptions and stereotypical thinking to appear when working on topics related to sexual reproduction and sexual dimorphism. Here we present, for continued discussion, a set of good-practice guidelines aimed at (1) helping to improve researchers' awareness of gender-biased assumptions underlying language use, generalizations, and interpretation of observations; and (2) providing recommendations to increase transparency, avoid problematic terminology, and improve study designs.
\end{abstract}

Keywords Female $\cdot$ Gender $\cdot$ Gender bias $\cdot$ Male $\cdot$ Sex $\cdot$ Sexual conflict $\cdot$ Sex differences $\cdot$ Sexual selection $\cdot$ Stereotype

In evolutionary studies, we often approach the biology of the sexes aiming to understand underlying processes behind differences, as well as similarities. Biologically, sexes are well defined based on a physical difference, i.e. the gamete size (Daly and Wilson 1983; Table 1: Glossary). In human societies, there are multiple constructions of gender (Thorne et al. 2019); here we focus on gender as socio-culturally constructed categories connected to the biological dichotomy between female and male (West and Zimmerman 1987; Table 1). With our human perspectives, sex-specific predictions for females and males may be unconsciously influenced

Authors in alphabetical order, united contribution.

Ingrid Ahnesjö

Ingrid.Ahnesjo@ebc.uu.se

1 Department of Ecology and Genetics/Animal Ecology, Uppsala University, Norbyvägen 18D, SE-75236 Uppsala, Sweden

2 Centre for Gender Research, Uppsala University, Thunbergsvägen 3G, Box 527, SE-75120 Uppsala, Sweden

3 Department of Organismal Biology/Systematic Biology, Uppsala University, Norbyvägen 18D, SE-75236 Uppsala, Sweden

4 Université de Lyon, Université Lyon 1, CNRS, Laboratoire de Biométrie Biologie Evolutive UMR 5558, Bât. Gregor Mendel, 43 Bd du 11 novembre 1918, 69622 Villeurbanne Cedex, France by culturally specific gender-biased assumptions (Table 1). This, in turn, may affect how biologists conduct evolutionary biology research.

Evolution is an ongoing process throughout which environmental influences, phenotypic plasticity and epigenetic effects are prominent (Bonduriansky and Day 2018; Fine et al. 2013). Thus, we should expect diverse outcomes of selective processes and gene-environment interactions, depending on the species, the context, the environment and the individuals. Yet, we often view and describe sex-differences in morphology and behaviour as relatively fixed and predictable (Lehtonen et al. 2016; Schärer et al. 2012), rather than diverse. To what extent do these fixed views reflect gender-biased assumptions underlying evolutionary research? Do gendered views emanate from patterns of male and female traits or does our perception of such patterns stem from pre-existing gender biases? We argue it is necessary to discuss the sex-specific predictions and assumptions we make in our scientific research in order to acknowledge the existing diversity in nature. We approached these questions and their ramifications in a workshop. The aim was (i) to critically discuss if and how gender-biased assumptions appear in evolutionary biology, (ii) to improve scientific practice by increasing awareness of gender biasedassumptions and (iii) to provide practical recommendations for recognizing and avoiding gender-biased assumptions in evolutionary research. 
Table 1 Glossary for usage of terms in this article

\begin{tabular}{lc}
\hline Term & Usage in this article \\
\hline Sex & $\begin{array}{c}\text { Sexes are two self-incompatible mating types that are distinguished by a difference in gamete } \\
\text { size (anisogamy), with the female sex producing larger gametes and the male sex smaller } \\
\text { ones (Daly and Wilson 1983) } \\
\text { The socio-culturally constructed, usually dichotomous set of characteristics and behaviours } \\
\text { according to biological sex (West and Zimmerman 1987) }\end{array}$ \\
Gender-biased assumption & Assumptions applied to the sexes based on stereotypical, socio-culturally defined gender views \\
\hline
\end{tabular}

Several evolutionary biology articles, as well as books, were discussed (see reference list) during the workshop and prompted our guidelines. Here, we will primarily present examples that constructively discuss the problem of genderbiased assumptions or illustrate some of our recommendations. We also considered feminist perspectives (Schiebinger 1999; Fehr 2018) on questions of representative sampling, danger of extrapolating, language use and the remaking of theoretical understanding.

We found that it is not uncommon in the introduction of papers to present sex differences that go beyond the gamete size as general, natural and prominent facts, with no or only few supporting citations. Such assumptions of generalized sex differences across taxa-for instance, "competitive" males, "choosy" and "caring" females-require specific support and an openness that the other sex may also display such traits. We argue there is potential for improvement here to present qualitative and quantitative differences as well as similarities among the sexes (for balanced examples, see Clutton-Brock 2007, 2017; Hare and Simmons 2019; Rosenthal 2017). When arguing that sexual traits and behaviours are consequences of anisogamy per se (Lehtonen et al. 2016; Schärer et al. 2012), we recommend providing the support for one's assertions, in particular, when based on long established arguments as in an "appeal to authority", e.g. Bateman (1948) and Trivers (1972). This is important as the ecology of a population, as well as other factors (not only gamete size) influence sex-differences in traits and behaviours (Clutton-Brock 2007, 2017; Forsgren et al. 2004). Furthermore, when discussing sex-biased mating rates and Bateman gradients (Anthes et al. 2017), we suggest that one should also address the critical scientific debate (Snyder and Gowaty 2007; Tang-Martinez 2005) in order to be transparent in reasoning and to avoid confirmation biases. We need to be aware that we may pay more attention to findings that confirm what we believe to be true, and that dominant model systems may prompt confirmation biases (Zuk et al. 2014). Thus, by approaching observations of nature with rigid views on what is considered typically male and female, we may limit our ability to include findings of diversity and variation when assuming that certain traits are only expressed in one sex. In general, explanatory frameworks should not exclude (i.e. make exceptions of) less common findings in a sex; it is variation to be acknowledged. The greater focus of sexual selection on males than on females can, for instance, be illustrated by a recent textbook study where a much higher number of images of male than female animals were used for illustrating sexual selection concepts (Fuselier et al. 2018). However, publications on sexual selection in females are increasingly appearing in the literature, as well as in mathematical models on female ornamentations (Fitzpatrick and Servedio 2018; Hare and Simmons 2019; Schlupp 2018). Such approaches may help us understand that sexual selection can operate in similar ways independently of sex, and that processes of sexual selection are not confined to one sex (Clutton-Brock 2007; Hare and Simmons 2019). Thus, there is an ongoing change in views on sexual selection, which is illustrated in continued discussions on the grey zones of sexual selection definitions (Alonzo and Servedio 2019).

Language itself is considered to be gendered (Beldecos et al. 1989; Ecklund et al. 2012), and its use is a powerful tool that requires care and precision. For instance, when describing similar behaviour, it is well documented that in scientific studies we use more activity-related words for describing males, while words related to passivity are used to describe females (Bertotti Metoyer and Rust 2011; Karlsson Green and Madjidian 2011). Another issue related to language is the use of "catchy" but misleading titles. Titles can serve to make research stand out and attract readers, but we strongly recommend refraining from using anthropomorphic terminology, or the use of terms related to human stereotypes, in titles and texts. Being conscious of the way we use metaphors, and especially avoiding anthropomorphisms that relate to sex and gender, is crucial. Several metaphors common in biological research may pose a particular challenge, as they may carry normative implications (Hankinson Nelson 2017) and sustain a bias towards viewing clear boundaries between sexual traits and a taken-for-granted dichotomy (Bergvall 2014). We suggest instead to use neutral, operational and descriptive language, especially in cases where metaphors or shorthand terms rely on readers' expectations. We recommend anthropomorphic terms such as "homosexual" (MacFarlane et al. 
2010) to be replaced by the descriptive term "same-sex" (Scharf and Martin 2013). Furthermore, concepts with connotations such as "sex-roles" should be avoided (Ah-King and Ahnesjö 2013). For example, Rosenthal (2017) uses the terms "courters" and "choosers" as operational descriptors, independent of sex. Alternatively, terms can be explicitly defined for the context within which they are used, as readers' intuitive interpretation of common language terms varies, especially between cultures. In accordance, we have explained the meaning of sex, gender and genderbiased assumptions for our context (Table 1). Many of us are unaware of the underlying assumptions about gender in language use. A simple self-test can be to switch male and female terms. If, for the author, the meaning of the sentence is changed beyond the simple change of sex, it may reveal a gender-bias in wording.

How and what we measure influences how we interpret information. Thus, general scientific rigor should be applied to ensure representative sampling of the sexes, unbiased trait measurements, behavioural observations, evaluation of alternative hypotheses, etc. This importance is well illustrated by a recent paper arguing for why males and females are to be included in laboratory animal studies in neurosciences (Shansky 2019) and examples of the problems that result from failing to include females in medical science and pharmacology studies are plenty (Perez 2019). Gender-biases can be enduring as illustrated by research on animal genitalia where, despite awareness of a male focus, female genitalia are still understudied (Ah-King et al. 2014). We recommend, whenever feasible, to measure the same parameters in the same way in all sexes. However, this recommended approach should not refrain from further investigation of a previously understudied sex. If a question is sex-specific and thus only measured in one sex, one should present the arguments for this approach so that the reader is able to assess whether the design is a consequence of gender-biased assumptions. Observing animal behaviour is a stimulating task and often involves the observer emotionally. If possible, we recommend letting observers that are blind to treatments and sex of the individuals execute the observations to minimize the risk of bias influencing the interpretation of observations in males or females, which may be a particular challenge for field-based observations.

By going beyond what is considered typically male and female, we allow for the recognition of a broad diversity of sex-differences, as well as similarities, in morphology and behaviour. With our guidelines, we hope to better acknowledge and characterize this diversity, and to help scientists conduct their research with clearer awareness of how their assumptions might influence their work. Here, we call for more transparency, more accurate language use and interpretations of findings, as well as less biased study designs. These guidelines aim to raise awareness about, facilitate identification of and help avoidance of genderbiased assumptions in evolutionary biology.

\section{Guidelines}

\section{Be Aware of Your Assumptions}

a. Reflect critically on assumptions of a priori sex differences.

b. Avoid presenting assumptions as facts. Interpret theoretical results as predictions, and not as empirical evidence.

c. Whenever possible, use naïve experimenters/observers, to minimize the risk that gender-biased expectations affect the measurements.

\section{Be Transparent}

a. Provide critical and thorough literature backgrounds as well as references and support for what may appear as taken-for-granted views or an "appeal to authority".

b. Attempt to study all sexes and justify the traits measured. If only one sex is studied, specify which sex and provide the rationale for why. When measuring sex-specific traits, reflect over relevance and comparability between sexes.

\section{Be Aware of Language Usage}

a. Use clearly defined or operational terms that minimize the risk of misinterpretation due to pre-existing expectations of the reader (e.g. use "same-sex behaviours" instead of "homosexual" or avoid using "sex roles" which has no universal biological meaning).

b. Avoid anthropomorphisms and using gender stereotypical terms (e.g. masculinity, femininity, divorce, adultery, emancipated etc.).

c. When being general, use descriptive terms without gender, for instance, use courters and choosers for whichever sex does the courting and the choosing (Rosenthal 2017).

\section{Be Careful When Generalizing}

a. Be clear and careful when claiming generality of results. Be aware of the underlying samples; one sex likely does not fully represent the population or the species.

b. Results that do not fit assumptions or patterns that are more uncommon are not exceptions - they represent variation that should be thoroughly discussed as such. 
Acknowledgements Open access funding provided by Uppsala University. These guidelines emanated as a result from a workshop and we are grateful to M. Ah-King for inspiration and for the support by ESEB equal opportunity funds, VINNOVA and Uppsala University. We are also thankful for comments by several reviewers.

\section{Compliance with Ethical Standards}

Conflict of interest The authors have no conflict of interest to declare.

Open Access This article is licensed under a Creative Commons Attribution 4.0 International License, which permits use, sharing, adaptation, distribution and reproduction in any medium or format, as long as you give appropriate credit to the original author(s) and the source, provide a link to the Creative Commons licence, and indicate if changes were made. The images or other third party material in this article are included in the article's Creative Commons licence, unless indicated otherwise in a credit line to the material. If material is not included in the article's Creative Commons licence and your intended use is not permitted by statutory regulation or exceeds the permitted use, you will need to obtain permission directly from the copyright holder. To view a copy of this licence, visit http://creativecommons.org/licenses/by/4.0/.

\section{References}

Ah-King, M., \& Ahnesjö, I. (2013). The "sex role" concept: An overview and evaluation. Evolutionary Biology, 40(4), 461-470. https ://doi.org/10.1007/s11692-013-9226-7.

Ah-King, M., Barron, A. B., \& Herberstein, M. E. (2014). Genital evolution: Why are females still understudied? PLoS Biology, 12(5), 1-7. https://doi.org/10.1371/journal.pbio.1001851.

Alonzo, S. H., \& Servedio, M. R. (2019). Grey zones of sexual selection: Why is finding a modern definition so hard? Proceedings of the Royal Society B: Biological Sciences, 286(1909), 20191325. https://doi.org/10.1098/rspb.2019.1325.

Anthes, N., Häderer, I. K., Michiels, N. K., \& Janicke, T. (2017). Measuring and interpreting sexual selection metrics: Evaluation and guidelines. Methods in Ecology and Evolution, 8(8), 918-931. https://doi.org/10.1111/2041-210X.12707.

Bateman, A. J. (1948). Intra-sexual selection in Drosophila. Heredity, 2, 349-368.

Beldecos, A., Bailey, S., Gilbert, S., Hicks, K., Kenschaft, L., Niemczyk, N., et al. (1989). The importance of feminist critique for contemporary cell biology. Feminism and Science, 3(1), 172.

Bergvall, V. (2014). Rethinking language and gender research: Theory and practice. London: Routledge.

Bertotti Metoyer, A., \& Rust, R. (2011). The egg, sperm, and beyond: Gendered assumptions in gynecology textbooks. Women's Studies, 40(2), 177-205. https://doi.org/10.1080/00497878.2011.537986.

Bonduriansky, R., \& Day, T. (2018). Extended heredity: A new understanding of inheritance and evolution. Princeton: Princeton University Press.

Clutton-Brock, T. (2007). Sexual selection in males and females. Science, 318(5858), 1882-1885. https://doi.org/10.1080/09540 121.2012.701726.

Clutton-Brock, T. (2017). Reproductive competition and sexual selection. Philosophical Transactions of the Royal Society B Biological Sciences. https://doi.org/10.1098/rstb.2016.0310.

Daly, M., \& Wilson, M. (1983). Sex, evolution, and behavior (2nd ed.). Boston: Willard Grant Press.

Ecklund, E. H., Lincoln, A. E., \& Tansey, C. (2012). Gender segregation in elite academic science. Gender and Society, 26(5), 693717. https://doi.org/10.1177/0891243212451904.
Fehr, C. (2018). Feminist philosophy of biology. In The Stanford encyclopedia of philosophy. https://plato.stanford.edu/archives/fall2 018/entries/feminist-philosophy-biology/

Fine, C., Jordan-Young, R., Kaiser, A., \& Rippon, G. (2013). Plasticity, plasticity, plasticity....and the rigid problem of sex. Trends in Cognitive Sciences, 17(11), 550-551. https://doi.org/10.1016/j. tics.2013.08.010.

Fitzpatrick, C. L., \& Servedio, M. R. (2018). The evolution of male mate choice and female ornamentation: A review of mathematical models. Current Zoology, 64(3), 323-333. https://doi. org/10.1093/cz/zoy029.

Forsgren, E., Amundsen, T., Borg, A. A., \& Bjelvenmark, J. (2004). Unusually dynamic sex roles in a fish. Nature, 429(6991), 551554. https://doi.org/10.1038/nature02562.

Fuselier, L., Eason, P. K., Jackson, J. K., \& Spaulding, S. (2018). Images of objective knowledge construction in sexual selection chapters of evolution textbooks. Science and Education, 27(5-6), 479-499. https://doi.org/10.1007/s11191-018-9978-7.

Hankinson Nelson, L. (2017). Biology and Feminism, a philosophical introduction. Cambridge: Cambridge University Press.

Hare, R. M., \& Simmons, L. W. (2019). Sexual selection and its evolutionary consequences in female animals. Biological Reviews, 94, 929-956. https://doi.org/10.1111/brv.12484.

Karlsson Green, K., \& Madjidian, J. A. (2011). Active males, reactive females: Stereotypic sex roles in sexual conflict research? Animal Behaviour, 81(5), 901-907. https://doi.org/10.1016/j.anbehav.2011.01.033.

Lehtonen, J., Parker, G. A., \& Schärer, L. (2016). Why anisogamy drives ancestral sex roles. Evolution, 70(5), 1129-1135. https:// doi.org/10.1111/evo.12926.

MacFarlane, G. R., Blomberg, S. P., \& Vasey, P. L. (2010). Homosexual behaviour in birds: Frequency of expression is related to parental care disparity between the sexes. Animal Behaviour, 80(3), 375-390. https://doi.org/10.1016/j.anbehav.2010.05.009.

Perez, C. C. (2019). Invisible women: Exposing data bias in a world designed for men. New York: Abrams Press.

Rosenthal, G. G. (2017). Mate choice. The evolution of sexual decision making from microbes to humans. Princeton, New Jersey: Princeton University Press.

Schärer, L., Rowe, L., \& Arnqvist, G. (2012). Anisogamy, chance and the evolution of sex roles. Trends in Ecology and Evolution, 27(5), 260-264. https://doi.org/10.1016/j.tree.2011.12.006.

Scharf, I., \& Martin, O. Y. (2013). Same-sex sexual behavior in insects and arachnids: Prevalence, causes, and consequences. Behavioral Ecology and Sociobiology, 67(11), 1719-1730. https://doi. org/10.1007/s00265-013-1610-x.

Schiebinger, L. (1999). Has feminism changed science?. Cambridge: Harvard University Press.

Schlupp, I. (2018). Male mate choice, female competition, and female ornaments as components of sexual selection. Current Zoology, 64(3), 321-322. https://doi.org/10.1093/cz/zoy037.

Shansky, R. M. (2019). Are hormones a "female problem" for animal research? Science, 364(6443), 825-826. https://doi.org/10.1126/ science.aaw7570.

Snyder, B. F., \& Gowaty, P. A. (2007). A reappraisal of Bateman's classic study of intrasexual selection. Evolution, 61(11), 2457-2468. https://doi.org/10.1111/j.1558-5646.2007.00212.x.

Tang-Martinez, Z. (2005). The problem with paradigms: Bateman's worldview as a case study. Integrative and Comparative Biology, 45(5), 821-830. https://doi.org/10.1093/icb/45.5.821.

Thorne, N., Yip, A. K. T., Bouman, W. P., Marshall, E., \& Arcelus, J. (2019). The terminology of identities between, outside and beyond the gender binary-A systematic review. International Journal of Transgenderism, 20(2-3), 138-154. https://doi.org/10.1080/15532 739.2019.1640654. 
Trivers, R. L. (1972). Parental investment and sexual selection. In B. Campbell (Ed.), Sexual selection and the descent of man, 18711971 (pp. 136-179). Chicago: Aldine.

West, C., \& Zimmerman, D. H. (1987). Doing Gender. Gender \& Society, $1,125-151$.

Zuk, M., Garcia-Gonzalez, F., Herberstein, M. E., \& Simmons, L. W. (2014). Model systems, taxonomic bias, and sexual selection: beyond drosophila. Annual Review of Entomology, 59(1), 321-338. https://doi.org/10.1146/annurev-ento-011613-162014.
Publisher's Note Springer Nature remains neutral with regard to jurisdictional claims in published maps and institutional affiliations. 